\section{Minihepcidins improve ineffective erythropoiesis and splenomegaly in a new mouse model of adult $\beta$-thalassemia major}

\section{Carla Casu, ${ }^{1 *}$ Roberta Chessa,${ }^{1 *}$ Alison Liu, ${ }^{1}$ Ritama Gupta, ${ }^{1}$ Hal Drakesmith, ${ }^{2}$ Robert Fleming, ${ }^{3}$ Yelena Z. Ginzburg, ${ }^{4}$ Brian MacDonald ${ }^{5}$ and Stefano Rivella ${ }^{1}$}

${ }^{1}$ Department of Pediatrics, Division of Hematology, The Children's Hospital of Philadelphia (CHOP), Philadelphia, PA, USA; ${ }^{2}$ MRC Human Immunology Unit, MRC Weatherall Institute of Molecular Medicine, University of Oxford, John Radcliffe Hospital, Oxford, UK; ${ }^{3}$ Department of Pediatrics, Saint Louis University School of Medicine, St. Louis, MO, USA; ${ }^{4}$ Division of Hematology and Medical Oncology, Tisch Cancer Center, Icahn School of Medicine at Mount Sinai, New York, NY, USA and ${ }^{5}$ Merganser Biotech Inc. King of Prussia, PA, USA

${ }^{*} C C$ and $R C$ contributed equally as co-first authors.

\section{ABSTRACT}

M inihepcidins are hepcidin agonists that have been previously shown to reverse iron overload and improve erythropoiesis in mice affected by non-transfusion-dependent thalassemia. Given the extreme anemia that occurred with the previous model of transfusiondependent thalassemia, that model was inadequate for investigating whether minihepcidins can improve red blood cell quality, lifespan and ineffective erythropoiesis. To overcome this limitation, we generated a new murine model of transfusion-dependent thalassemia with severe anemia and splenomegaly, but sufficient red cells and hemoglobin production to test the effect of minihepcidins. Furthermore, this new model demonstrates cardiac iron overload for the first time. In the absence of transfusions, minihepcidins improved red blood cell morphology and lifespan as well as ineffective erythropoiesis. Administration of a minihepcidin in combination with chronic red blood cell transfusion further improved the ineffective erythropoiesis and splenomegaly and reversed cardiac iron overload. These studies indicate that drugs such as minihepcidins have therapeutic potential for patients with transfusion-dependent thalassemia.

\section{Introduction}

Non-transfusion and transfusion-dependent thalassemia (NTDT and TDT, respectively) are characterized by imbalanced synthesis of $\alpha$-and $\beta$-globin chains, leading to the formation of unstable $\alpha$-globin chain/heme aggregates (hemichromes) in erythroid cells. Hemichromes impair the differentiation and survival of erythroid progenitors as well as the lifespan of enucleated red blood cells (RBC). ${ }^{1-6}$

Both NTDT and TDT patients suffer from iron overload and require chronic iron chelation therapy to prevent major complications, such as liver and heart failure. . $^{5.9}$ The mechanism leading to iron accumulation in organs is different in NTDT vs. TDT. $., 6,10,11$ In NTDT, iron overload is likely mediated by a variety of factors, including increased erythropoiesis, hypoxia and the contribution of factors such as erythroferrone, which suppresses hepcidin synthesis in the liver. ${ }^{12-16}$ Because hepcidin functionally inhibits iron egress from cells by binding and internalizing the iron transporter ferroportin in enterocytes, iron absorption is increased under conditions of reduced hepcidin synthesis. ${ }^{3,16-18}$ Additionally, in hypoxic conditions, synthesis of molecules responsible for mediating iron absorption (including ferroportin) are increased in the duodenum, further contributing to the iron overload in NTDT, ${ }^{4,19,20}$ In contrast to NTDT patients, TDT patients require chronic RBC transfusion for survival., ${ }^{9,18,21}$ Because transfused RBC ultimately undergo senescence and require removal by splenic and liver macrophages and because there is no physio-
Ferrata Storti Foundation

Haematologica 2020

Volume 105(7):1835-1844

\section{Correspondence:}

STEFANO RIVELLA

rivellas@email.chop.edu

Received: November 19, 2018.

Accepted: September 26, 2019.

Pre-published: October 3, 2019.

doi:10.3324/haematol.2018.212589

Check the online version for the most updated information on this article, online supplements, and information on authorship \& disclosures: www.haematologica.org/content/105/7/1835

\section{(C)2020 Ferrata Storti Foundation}

Material published in Haematologica is covered by copyright. All rights are reserved to the Ferrata Storti Foundation. Use of published material is allowed under the following terms and conditions:

https://creativecommons.org/licenses/by-nc/4.0/legalcode. Copies of published material are allowed for personal or internal use. Sharing published material for non-commercial purposes is subject to the following conditions:

https://creativecommons.org/licenses/by-nc/4.0/legalcode, sect. 3. Reproducing and sharing published material for commercial purposes is not allowed without permission in writing from the publisher. 
logical way of excreting the iron recycled from these cells, continuous infusion of $\mathrm{RBC}$ is the primary reason for iron overload in TDT patients. ${ }^{18,21,22}$

Mouse models of $\beta$-thalassemia intermedia (e.g. Hbb $b^{\text {th } 3 /+}$ mice) exhibit ineffective erythropoiesis, anemia and reduced or inappropriately normal hepcidin synthesis, but do not require RBC transfusion for survival, similarly to NTDT patients. Minihepcidins function as hepcidin agonists, target ferroportin, and reduce iron absorption and transferrin saturation. ${ }^{23,24}$ We and others showed that administration of minihepcidins or agents that induce hepcidin expression in $\mathrm{Hb}^{\text {th } 3 /+}$ mice decreased transferrin saturation, heme synthesis, hemichrome formation, and improved RBC lifespan, anemia, and splenomegaly. ${ }^{17,25-29}$ Taken together, these experiments demonstrated the potential benefits of minihepcidins in NTDT. However, it is unclear whether minihepcidins would improve anemia, transfusion requirements, and iron overload in TDT.

Based on the pathophysiology of TDT and the effect of minihepcidins on iron metabolism and erythropoiesis in NTDT, we speculate that minihepcidins may: (i) improve ineffective erythropoiesis; (ii) increase RBC lifespan and reverse anemia; (iii) decrease $\mathrm{RBC}$ transfusion requirements (decrease frequency of transfusion); (iv) reverse splenomegaly and extramedullary erythropoiesis; (v) decrease indications for splenectomy; and (vi) reverse iron overload in TDT patients.

Multiple existing mouse models of $\beta$-thalassemia intermedia harbor different mutations leading to decreased mouse $\beta$-globin genes synthesis, triggering ineffective erythropoiesis and anemia (Figure 1A-C). However, some animals do not require RBC transfusion for survival, while others produce very few RBC. . $^{30-33}$ For example, $H b b^{\text {th } / \text { th }}$ mice carry a homozygous spontaneous deletion of $3.7 \mathrm{~Kb}$ containing the $\beta$-major gene and $2 \mathrm{~Kb}$ of the $5^{\prime}$ flanking region, including the promoter (Figure 1A). ${ }^{34}$ $H b b^{t h 2 /+}$ mice were created by inserting a neomycin-resistant cassette into exon 2 of the $\beta$-major gene such that heterozygotes are mildly anemic while homozygotes die perinatally due to severe anemia (Figure 1B). ${ }^{35} \mathrm{Hb}^{\text {th } 3 /+}$ mice have one copy of the normal $\beta$-globin cluster and an allele with a deletion of both the $\beta$-major and $\beta$-minor genes (Figure $1 \mathrm{C}$ ), resulting in moderate anemia that is not severe enough to require transfusion, a phenotype similar to that of $\mathrm{Hb}^{\mathrm{th} / \mathrm{th} /}$ mice. ${ }^{36,37}$ Homozygous $\mathrm{Hb}^{b^{\text {th } 3 / t h 3}}$ mice die perinatally, preventing their use as an adult model of TDT. ${ }^{36}$

We previously used a transplant model in which fetal liver cells from E13.5-15.5 day $\mathrm{Hbb}^{\text {th } 3 \text { th } 3}$ embryos are transplanted into irradiated wildtype (WT) syngeneic mice. ${ }^{36-38}$ Successful engraftment of $\mathrm{Hb}^{\mathrm{th} 3 \mathrm{th}^{\mathrm{t}} \mathrm{s}}$ fetal liver cells led to ineffective erythropoiesis and severe anemia resulting in death 3 months after transplantation if the animals were not transfused. ${ }^{16,38,39}$ This and other models were utilized to study dysregulated iron metabolism in $\beta$-thalassemia major. ${ }^{16,35-39}$ However, Hbb ${ }^{\text {th } 3 \text { th }}$ mice are characterized by such low hemoglobin and RBC production that they make testing drugs, such as minihepcidins that have the potential to modify RBC quality and lifespan and improve ineffective erythropoiesis, complex if not impossible.

To assess the efficacy of minihepcidins in TDT, we generated a new mouse model $\left(H b b^{\text {th/th2 }}\right)$ that closely resembles the human TDT phenotype (Figure 1D). Our aim was to use combinations of already existing mutations in order to generate a model intermediate in severity to those already in use, in which some RBC are produced although their synthesis is insufficient to support long-

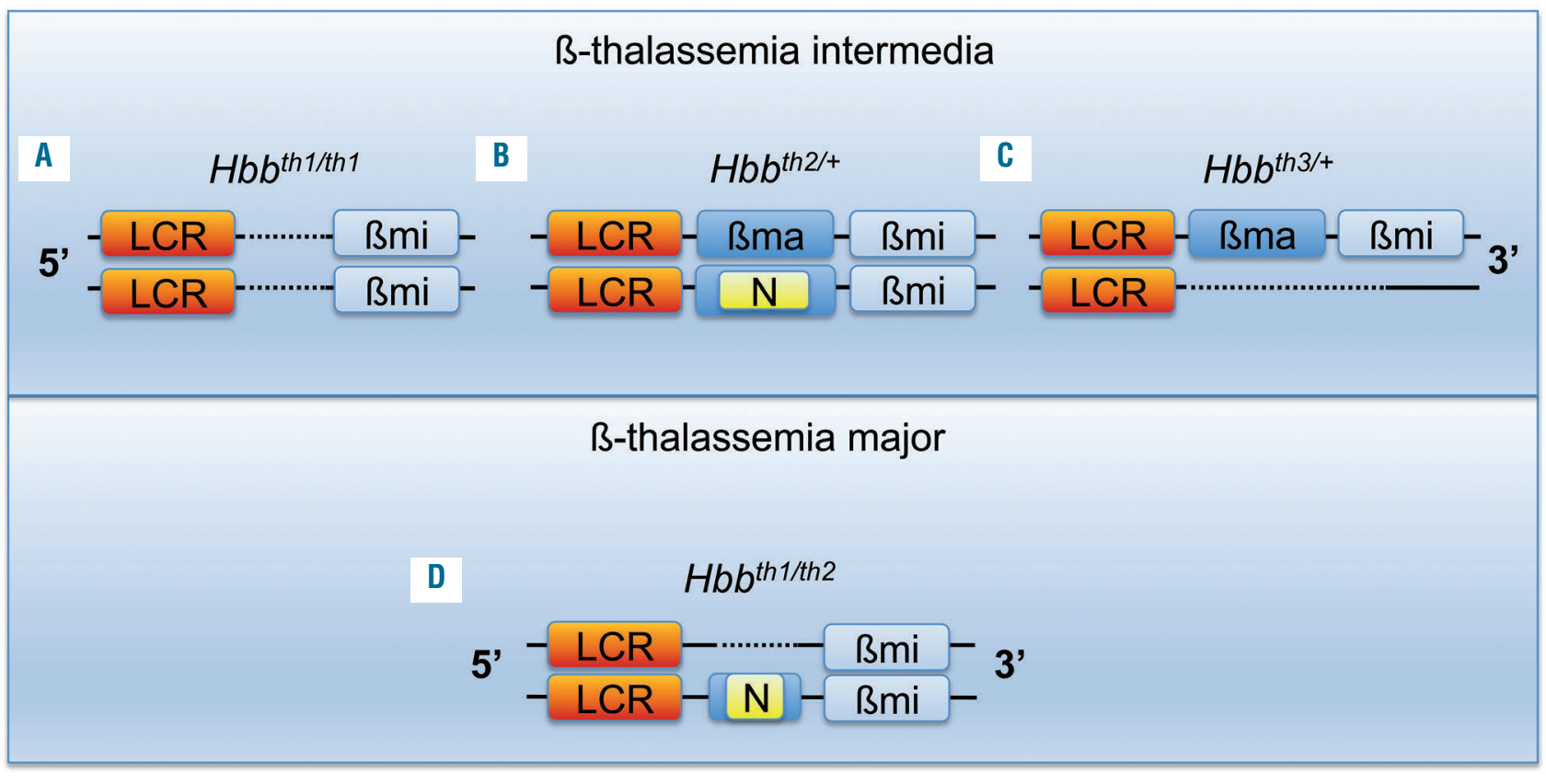

Figure 1. Genetic makeup of established mouse models of $\beta$-thalassemia intermedia and a new model of $\beta$-thalassemia major. (A-C) Mouse models of $\beta$-thalassemia Intermedia: (A) $H b b^{\text {th } 1 / \text { th } 1}$, (B) $H b b^{\text {th } 2 /+}$, (C) $H b b^{\text {th } 3 /+}$ and (D) a new mouse model of $\beta$-thalassemia major: Hbb $b^{\text {th } 1 / t h 2}$. The mouse $\beta$-globin locus is represented in the 5 ' to 3 ' orientation; for simplicity, only the $\beta$-globin genes are indicated; not in scale. LCR: $\beta$-globin locus control region; $\beta$ ma: $\beta$-globin major gene; $\beta$ mi: $\beta$-globin minor gene; N: neomycin gene. Dotted lines represent DNA deletions. 
term survival in the absence of transfusion. Using these mice, we demonstrate the potential beneficial effect of minihepcidins in mice affected by TDT which were or were not given transfusions.

\section{Methods}

\section{Animal models}

$\mathrm{Hbb}^{\text {tht tht }}$ mice (B6.D2-Hbb ${ }^{\text {d3th }} / \mathrm{BrkJ}$ stock n. 000996) were

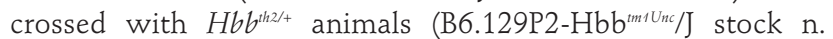
002204). ${ }^{34-36}$ All recipient mice were 8 - to 12 -week old females transgenic for either green fluorescent protein (C57BL/6$\operatorname{Tg}\left(\right.$ UBC-GFP)30Scha/J) ) $^{40}$ or B6.SJL-Ptprc ${ }^{a}$ Pepc $^{b} /$ BoyJ (known as Pep Boy). The Pep Boy mice allow us to discriminate between endogenous cells [which carry the differential Ptprc pan-leukocyte marker (commonly known as CD45.1 or Ly5.1)] from the donor fetal liver cells (which carry the CD45.2 or Ly5. variant); similarly, $\mathrm{GFP}^{+}$donors can be distinguished from GFP- recipient source RBC. Blood samples were analyzed as previously described. ${ }^{3,41}$

\section{Hematopoietic chimeras and genotyping}

Donor fetal liver cells were harvested from embryos (E13.515.5 days) obtained by intercrossing $H b b^{\text {tht/hth }}, H_{b} b^{\text {th2/ }}$, or WT mice. Embryonic genotypes were screened by DNA extraction (KAPA Biosystems, Kapa Mouse Genotyping Kit hotstart, KK7352) and polymerase chain reaction analysis (see Online Supplementary Tables S1 and S2). Fetal liver cells were kept on ice and resuspended in sterile phosphate-buffered saline (ThermoFisher PBS, Ph 7.4, CAT 10010023). To establish bone marrow chimeras, $2.0-5.0 \times 10^{6}$ cells were injected retro-orbitally into each of the irradiated female recipients. Recipient mice were irradiated with $10 \mathrm{~Gy}$ (split dose of $2 \times 5 \mathrm{~Gy}$ ) on the day of transplantation (ISOVOLT Titan E Series X-Ray Generators).

\section{Blood transfusion}

Transfusion was performed as previously described. ${ }^{16}$ Starting 2 months after transplantation, mice were transfused weekly via retro-orbital venous plexus with $300 \mu \mathrm{L}$ freshly harvested blood from normal healthy C57BL/6 mice or GFP. The first transfusion was delivered at the same time as the first minihepcidin administration. The last transfusion was delivered 1 week before the last minihepcidin injection.

\section{Mouse serum erythroferrone measurement}

The immunoaffinity liquid chromatography-tandem mass spectrometry assay to quantify total erythroferrone protein levels in mouse serum was developed in-house using surrogate peptide analysis. Briefly, total erythroferrone from $25 \mu \mathrm{L}$ serum was enriched using a biotinylated mouse anti-erythroferrone antibody (Drakesmith Lab) by diluting serum into $75 \mu \mathrm{L}$ of phosphate-buffered saline-Tween and incubating with antibody at $30^{\circ} \mathrm{C}$ for $4 \mathrm{~h}$ with interval mixing at $600 \mathrm{rpm}$. Magnetic streptavidin beads were added and incubated for an additional 30 min with interval mixing at $1200 \mathrm{rpm}$. The bound erythroferrone protein was then eluted from the beads using hydrochloric acid and processed for digestion using Promega trypsin-LysC enzyme at $37^{\circ} \mathrm{C}$ overnight. The liquid chromatography-tandem mass spectrometry quantification was carried out by monitoring two unique erythroferrone-specific surrogate peptides (EFOLLLK and SGSHFSAILLGL) using a standard curve generated with a recombinant mouse erythroferrone-Fc protein construct. Levels were measured with a lower limit of quantification (LLOQ) of $0.25 \mathrm{ng} / \mathrm{mL}^{.42-44}$

\section{Statistics}

Bars represent standard deviation (SD). When multiple comparisons were needed, statistical analysis was performed using ordinary one-way or two-way analysis of variance (ANOVA) with the Tukey or Sidak adjustment for multiple comparisons. An unpaired two-tailed Student $t$-test was used for comparisons between two groups. $P$ values $<0.05$ are considered statistically significant. All data were analyzed using GraphPad Prism version 7 (Microsoft GraphPad Software, La Jolla, CA, USA). Data for WT fetal liver cells are presented as a reference.

\section{Animal study approval}

All animal studies were conducted under protocols approved by the Institutional Animal Care and Use Committee of The Children's Hospital of Philadelphia.

\section{Results}

Generation of a new mouse model of $\beta$-thalassemia major or transfusion-dependent thalassemia

We hypothesized that intercrossing $H b b^{\text {th } 1 / t h 1}$ and $H b b^{\text {th2/ }}$ mice (Figure 1A, B) could generate animals that are able to produce $\mathrm{RBC}$, but with insufficient levels of adult hemoglobin for long-term survival (Figure 1D). At birth $H_{b b^{\text {th }} / \text { th } 2}$ pups were extremely pale but alive (for up to $8 \mathrm{~h}$ ) and died despite transfusion (Online Supplementary Figure S1A) likely due to irreversible damage associated with the severe hypoxia in late gestation. We then focused on generating mice through transplantation of $H b b^{\text {th } 1 \text { th }}$ fetal liver cells into recipient transgenic animals expressing GFP or Pep Boy mice $\left[H b b^{\text {th } 1 \text { th } 2}\right.$ bone marrow chimeras $\left.\left(H b b^{\text {th } 1 / \text { th } 2} \mathrm{BMC}\right)\right]$ (Online Supplementary Figures S1B and S2A, B; Online Supplementary Table $S 1$ and S2). The $\mathrm{GFP}^{+}$and the Pep Boy (CD45.1) mice were utilized to monitor the chimerism of circulating $\mathrm{RBC}$ over time (GFP vs. GFP+ $\mathrm{RBC}$ ) or bone marrow leukocytes (CD45.2 vs. CD45.1) and assess engraftment of donor cells. The resulting models demonstrate the desired phenotype 2 months after transplantation, including production of GFP RBC or CD45.2 bone marrow leukocytes and anemia (Online Supplementary Figure S3A, B, Figure 2).

\section{$H \boldsymbol{H b} \boldsymbol{b}^{\text {th1/th2 }} \mathrm{BMC}$ animals showed features of $\beta$-thalassemia major, requiring transfusion for long-term survival}

Two months after transplantation, analysis of the hematologic parameters indicated that $H b b^{\text {th/ } / \text { th } 2} \mathrm{BMC}$ mice produce few $\mathrm{RBC}$, low hemoglobin levels, but high reticulocyte counts (Figure 2A-C). Hbb $b^{\text {th } / \text { th } 2}$ BMC mice showed the largest increase in spleen weight (Figure 2D). Peripheral blood smears confirmed more severe anisocytosis, poikilocytosis and hypochromasia (Figure 2E) than in models of NTDT. Because Hbb ${ }^{\text {th } / \text { th }}$ BMC mice do not require transfusion for survival for up to 4 months after transplantation, we analyzed the effect of minihepcidins in the absence of transfusion. After this period, $\mathrm{Hb}^{\text {th } / \mathrm{th}^{2} \text { BMC }} \mathrm{BMice}$ showed exacerbation of their anemia, incompatible with survival.

\section{Administration of minihepcidins ameliorated red blood cell lifespan, ineffective erythropoiesis, anemia and splenomegaly in untransfused $\boldsymbol{H} \boldsymbol{b} \boldsymbol{b}^{\text {th1/th2 }} \mathrm{BMC}$ mice \\ $H b b^{\text {th } 1 / \text { h } 2} \mathrm{BMC}$ were treated with two doses of minihep- cidins, $2.625 \mathrm{mg} / \mathrm{kg}$ [(low dose (MH_L)] or $5.25 \mathrm{mg} / \mathrm{kg}$}


[high dose (MH_H)] 2 months after transplantation. The experimental design is shown in Online Supplementary Figure $4 A, B$. The duration of the treatment was selected based on the findings of our previous pharmacokinetic studies. ${ }^{28}$ Compared to controls (V-vehicle), administration of minihepcidins improved hematologic parameters in a dose-dependent manner. Using the lowest dose, we observed a trend of improved parameters, with the improvement reaching statistical significance with the highest dose. RBC count and hemoglobin concentration were statistically significantly improved in animals treated with the high dose (Figure 3A, B). Similarly, reticulocyte count and splenomegaly decreased more in $\mathrm{MH} \_\mathrm{H}-$ treated $\mathrm{Hbb}^{\text {th } / \text { th } 2} \mathrm{BMC}$ mice (Figure $\left.3 \mathrm{C}, \mathrm{D}\right)$. We then focused only on the highest dose. Minihepcidin administration also decreased hemichrome formation (Figure $3 \mathrm{E}$ ) and reactive oxygen species production (Figure $3 \mathrm{~F}$ ). Accordingly, RBC morphology (Figure 4A) and lifespan (Figure 4B) improved in MH_H-treated mice, relative to vehicle-treated $H b b^{\text {th } 1 / \text { th } 2} \mathrm{BMC}$ mice. Flow cytometric analysis of bone marrow and spleen samples (Figure 4C) demonstrated improved ineffective erythropoiesis in minihepcidin-treated $H b b^{\text {th } / \text { th } 2}$ BMC mice as the percentage (Figure 4D, E) of erythroid progenitor cells decreased compared to that of mature RBC.
Administration of minihepcidins ameliorated iron overload in untransfused $\mathbf{H b}^{\text {th } 1 / \text { th } 2}$ BMC mice

As erythropoiesis improved in $\mathrm{Hb}^{\text {th } 1 / \text { th } 2} \mathrm{BMC} \mathrm{MH} \_\mathrm{H}-$ treated mice, we investigated whether minihepcidins had a beneficial effect on endogenous hepcidin synthesis and iron metabolism. Hbb ${ }^{\text {th } / \text { th } 2} \mathrm{BMC}$ mice treated with vehicle demonstrated a significant increase in serum erythroferrone levels compared to WT animals, but a reduction in these values when treated with MH_H (Table 1, Figure $5 \mathrm{~A})$. Endogenous serum hepcidin concentrations were different between untreated and treated animals (Figure $5 \mathrm{~B}$ ), but no significant differences were observed in transferrin saturation levels (Figure 5C). However, serum iron levels decreased significantly in $\mathrm{MH}$ _H-treated $\mathrm{Hbb}^{\text {th } 1 \text { th }}$ BMC mice (Figure 5D). Moreover, Hbb $\bar{b}^{\text {tht th } 2} \mathrm{BMC}$ MH_H-treated mice showed significant reductions of iron by $\sim 33 \%$ and $\sim 77 \%$ in the liver and spleen, respectively, but not in the kidney (tissue iron content in the kidney not shown). (Figure 5E, F and Online Supplementary Figure S5).

Minihepcidin treatment ameliorated ineffective erythropoiesis, reversed splenomegaly, and reduced serum iron and heart iron concentration in transfused $\mathrm{Hbb}^{\text {th1/th2 }} B M C$ mice

Compared to $H b b^{\text {thrthth }}$ BMC mice treated with vehicle,
A

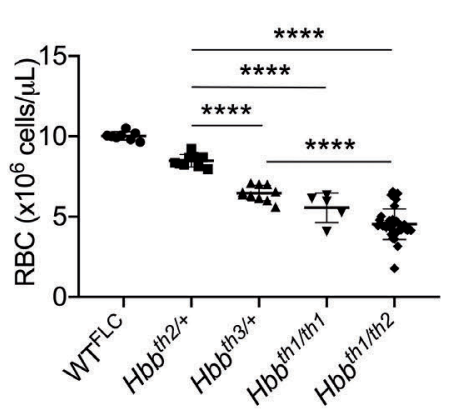

D

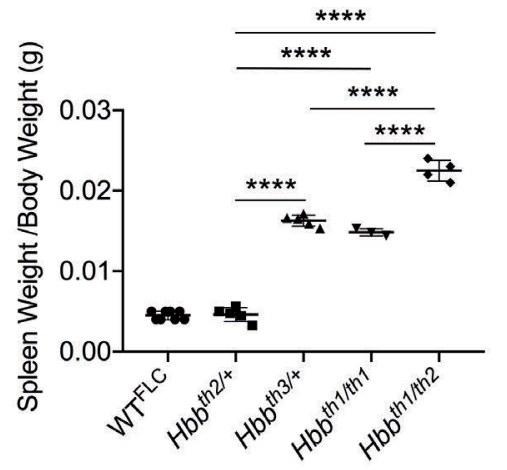

B

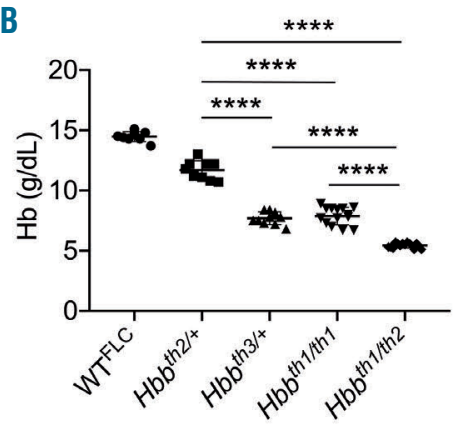

E

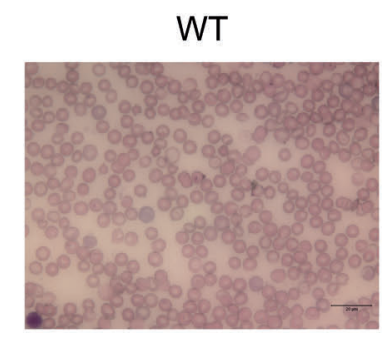

C

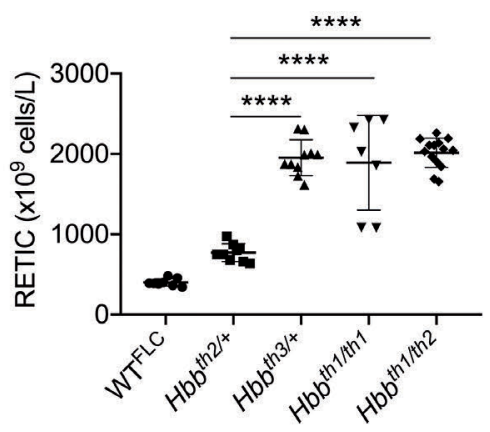

$H b b^{\text {th1 } 1 \text { th } 1}$

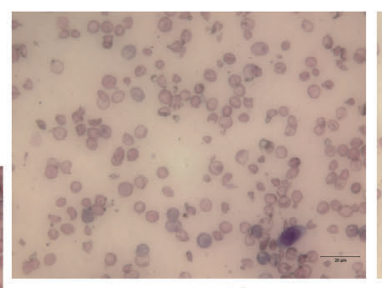

$H b b^{t h 3 /+}$

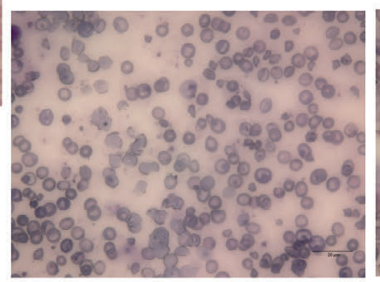

$H b b^{t h 2 /+}$

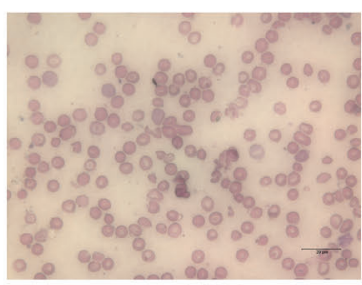

$H b b^{\text {th } 1 / \text { th } 2}$

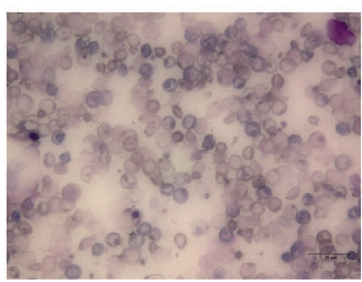

Figure 2. Complete blood count analysis of animals affected by $\beta$-thalassemia intermedia or major. (A) Red blood cell (RBC) number, (B) hemoglobin (Hb) levels, (C) reticulocytes (RETIC) count and (D) spleen weight. Bars represent standard deviation. $* * * * P \leq 0.001$. (E) RBC morphology (shown by Giemsa staining of peripheral blood smears) of wildtype (WT), $\beta$-thalassemia intermedia and $H b b^{\text {th1/th2 }}-B M C$ mice. 

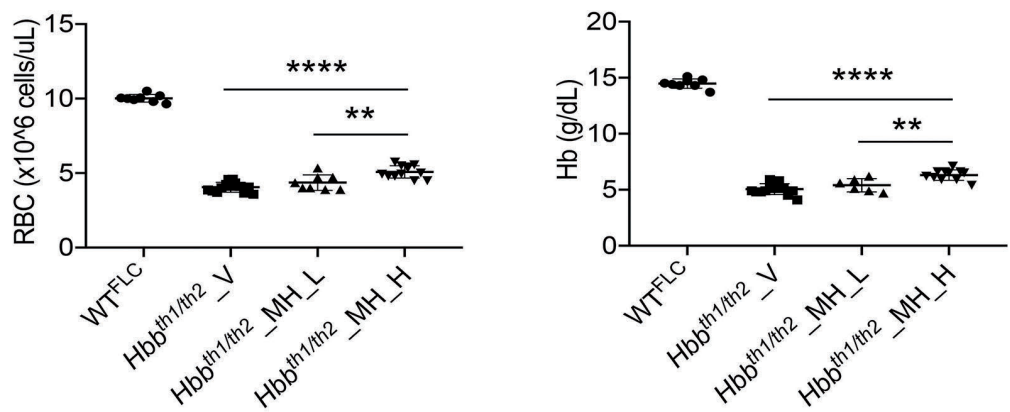

C

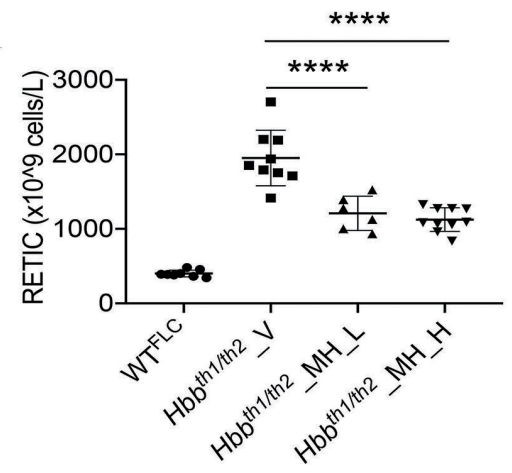

D

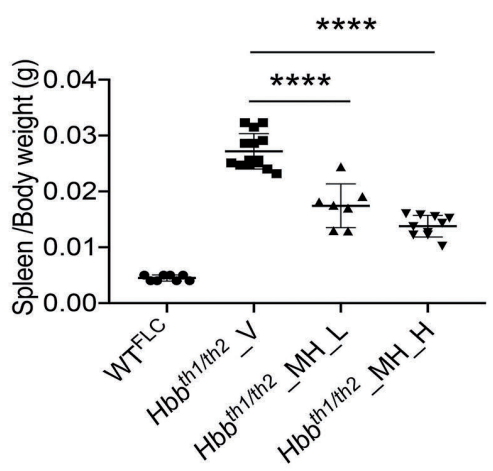

E

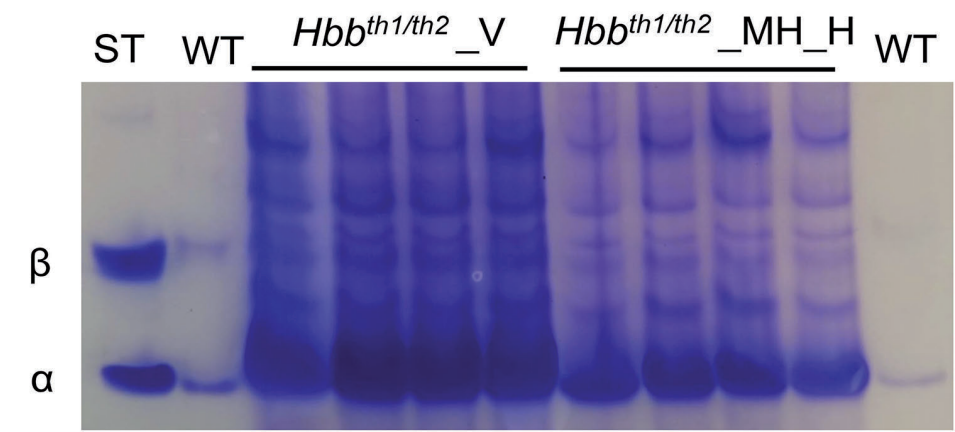

$\mathbf{F}$

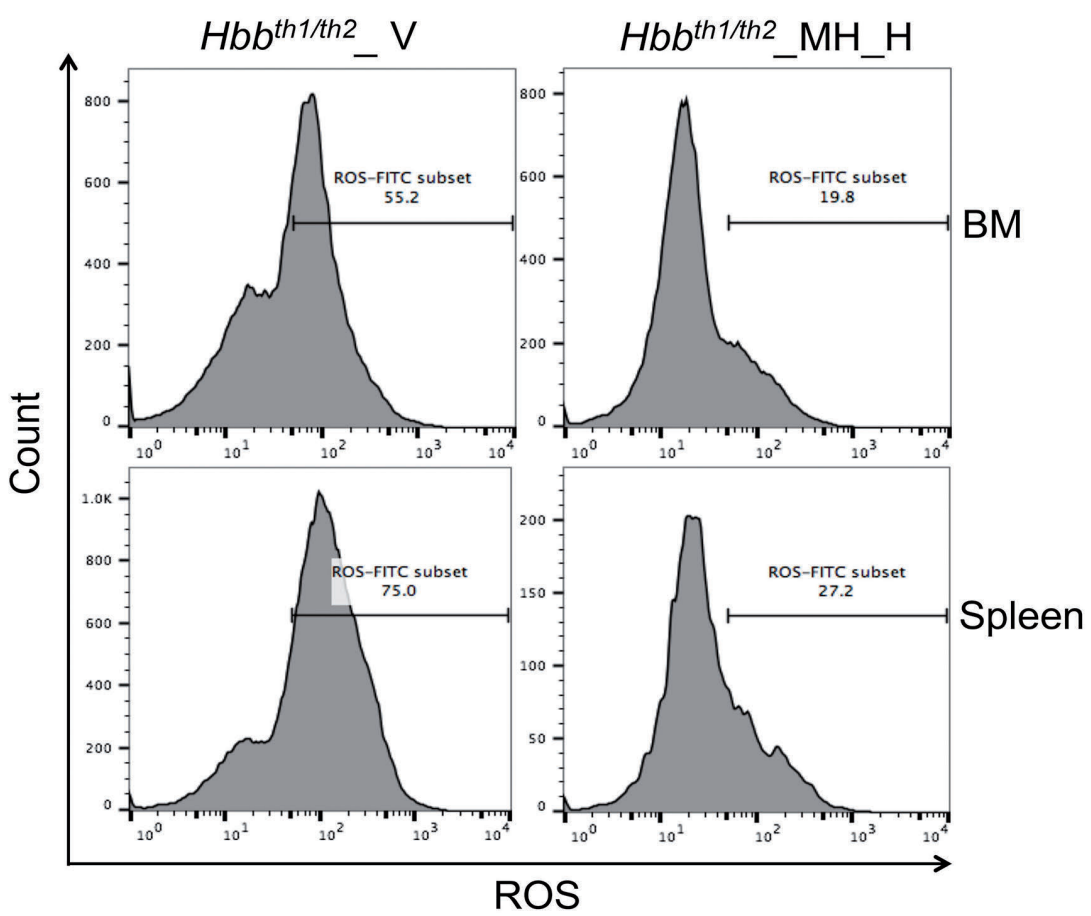

Figure 3. The effect of minihepcidin on complete blood count and splenomegaly in $H_{b b^{\text {th1/th2 }}-B M C}$ mice. Administration of a low dose of minihepcidin ( $\mathrm{MH} \mathrm{L}$ ) (2.625 $\mathrm{mg} / \mathrm{kg})$ or a high-dose $(\mathrm{MH} / \mathrm{H})(5.25$ $\mathrm{mg} / \mathrm{kg}$ ) to $H b b^{\text {th1/th2 }}-\mathrm{BMC}$ mice resulted in dose-dependent increases in (A) red blood cell (RBC) count and (B) hemoglobin $(\mathrm{Hb})$ concentration and decreases in $(C)$ reticulocyte (RETIC) count and (D) spleen weight. Bars represent the standard deviation. $\quad * * * * P \leq 0.001$ $* * P \leq 0.01$. (E) Minihepcidin administration also decreased hemichrome formation. (F) Flow cytometry studies of bone marrow and spleen erythroid populations of $\mathrm{Hbb}^{\text {th1/th2 }}-\mathrm{BMC}$ mice treated with $\mathrm{MH}$ _H showed reduced levels of reactive oxygen species. BM: bone marrow; ROS: reactive oxygen species. 
A

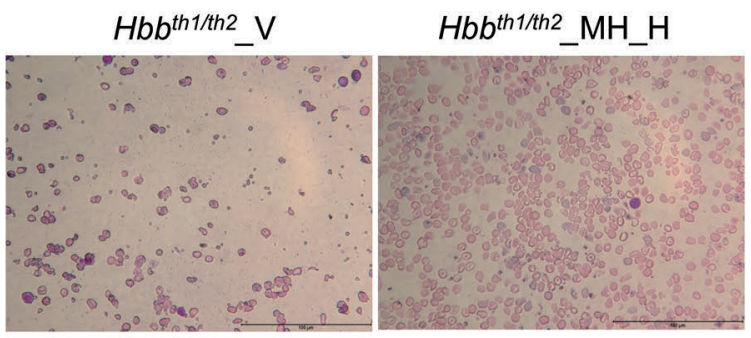

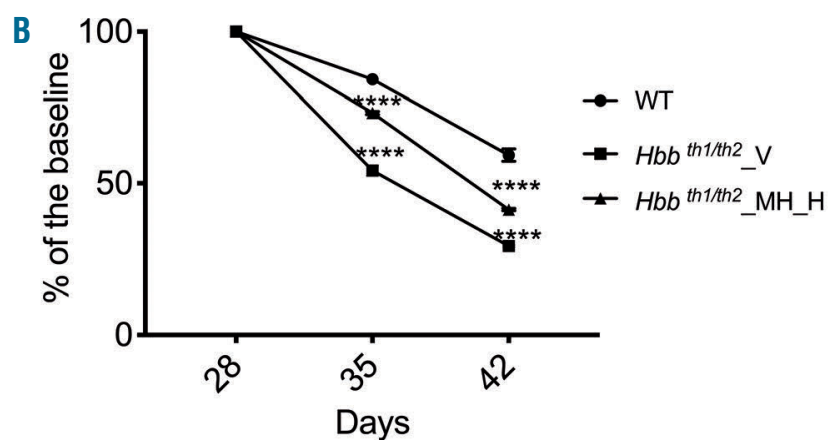

D
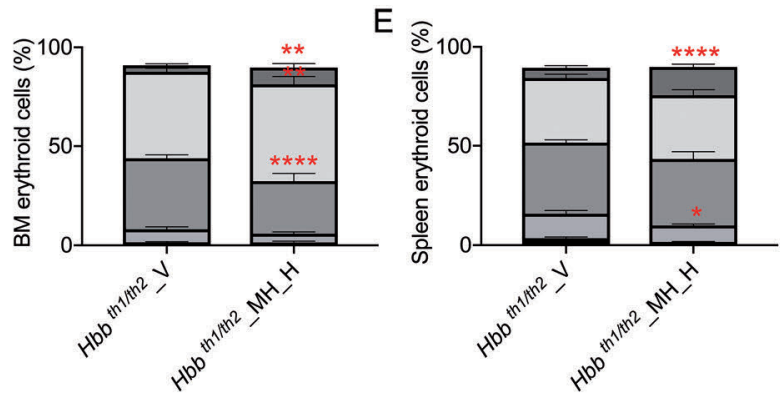

- ProErytroblast $\square$ Basophilic E. $\square$ Polycromatic E. $\square$ Ortho/Reticulocytes $\square$ Erythrocytes

Figure 4. The iron-restrictive effect of minihepcidin improved ineffective erythropoiesis in $H_{b b^{\text {th }} 1 / t h 2}-B M C$ mice. Minihepcidin improved (A) red blood cell (RBC) morphology and (B) RBC lifespan [statistics are determined comparing animals treated with vehicle (V) vs. high-dose minihepcidin (MH_H)]. (C) Minihepcidin also improved erythropoiesis in the bone marrow (BM) and spleen of $H b b^{\text {th1/th2 }}-B M C$ mice. (D, E) Flow activated cell sorting analysis of the percentage of BM (D) and splenic (E) erythroid cells using CD44 ${ }^{+}$and Ter119+ cells ( $n=4-5$ animals per group). Results are presented as means \pm standard deviation: $* * * * P \leq 0.001, * * P \leq 0.01, * P \leq 0.05$.

blood transfusion in animals treated or not with $\mathrm{MH} \_\mathrm{H}$ (see experimental design in Online Supplementary Figure $S 4 B$ ) resulted in increased RBC count and hemoglobin concentration, and decreased reticulocyte count and serum erythropoietin concentration (Figure 6A-D). Furthermore, flow cytometric analysis of bone marrow and splenic erythroid cells demonstrated that the combination of MH_H and blood transfusion further reduced the total number of erythroid progenitors compared to blood transfusion alone, indicating an improvement of ineffective erythropoiesis (Online Supplementary Figure S6A-C).

Transfusion alone in $H b b^{\text {tht } / \text { th }}$ BMC mice resulted in significantly increased serum hepcidin (Figure 7A), likely due to suppression of both serum erythropoietin concentration (Figure 6D) and endogenous erythropoiesis (Online Supplementary Figure S6). Administration of $\mathrm{MH} \_\mathrm{H}$ (with and without blood transfusion) had little effect on transferrin saturation (Figure 7B), but improved serum iron levels (Figure 7C) in non-transfused $\mathrm{Hbb}^{\text {tht/hth }} \mathrm{BMC}$ mice. Compared to $\mathrm{Hbb}^{\text {tht }}$ th $\mathrm{BMC}$ mice treated with vehicle alone, transfusion significantly decreased liver iron concentration (Figure 7D, Online Supplementary Figure S7), likely due to the increased levels in serum hepcidin (Figure 7A), but no further decrease was observed in $\mathrm{MH}$ _H-treated transfused $H b b^{\text {tht } / \text { th }}$ BMC mice.

Appreciable iron deposition in the heart makes our model helpful to study a pathological feature extremely relevant in patients affected by thalassemia major. In par-
Table 1. Serum erythroferrone measurements.

\begin{tabular}{|c|c|c|}
\hline $\begin{array}{l}\text { Erythroferrone ng/mL } \\
\text { WT }\end{array}$ & $H b b^{\text {th1/th2 }-V}$ & $H b b^{\text {th1/th2 }} C^{M H}$ H $^{* * * *}$ \\
\hline 1.0 & 9.6 & 4.3 \\
\hline LLOQ & 17.1 & 8.5 \\
\hline LLOQ & 13.0 & 7.0 \\
\hline 2.2 & 14.3 & 6.8 \\
\hline LLOQ & 15.2 & 7.7 \\
\hline LLOQ & 9.6 & 4.3 \\
\hline 2.4 & 17.1 & 8.5 \\
\hline
\end{tabular}

Serum erythroferrone levels in wildtype (WT) and thalassemic animals, treated with vehicle $(\mathrm{V})$ or a high dose of minihepcidin (MH_H). A statistically significant differ-

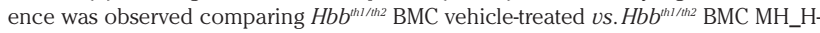
treated animals $\left({ }^{* * *} P \leq 0.001\right)$. The lower limit of quantification (LLOQ) in wildtype animals was $0.25 \mathrm{ng} / \mathrm{mL}$.

ticular, when we looked at the iron concentration in the heart, we observed that minihepcidins in combination with a transfusion regimen significantly reduced iron content (Figure 7E). Furthermore, as minihepicidins enable iron sequestration and reduce ineffective erythropoiesis, we postulate that the decreased erythroid mass also reduces the amount of iron utilized, leading to a relative normalization of transferrin saturation and parenchymal iron deposition. Furthermore, $\mathrm{MH} \_\mathrm{H}$ treatment in transfused $H_{b b^{\text {thth } / \text { h }}} \mathrm{BMC}$ mice decreased total spleen iron 
A

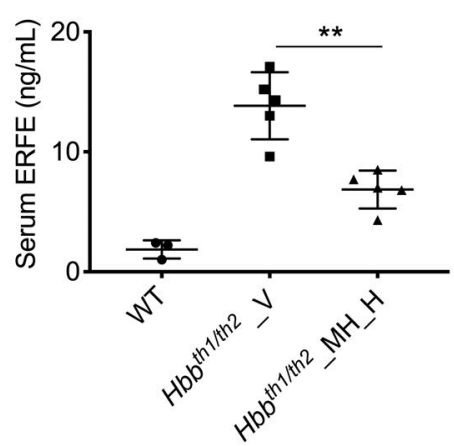

D

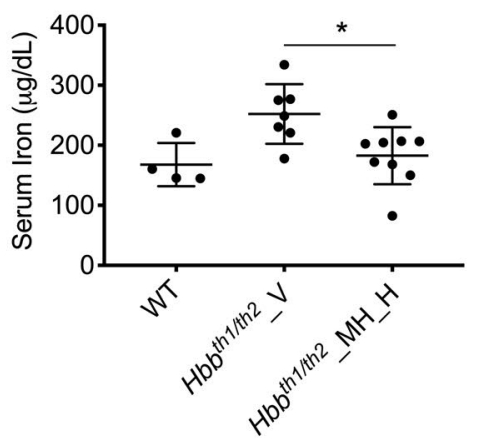

B

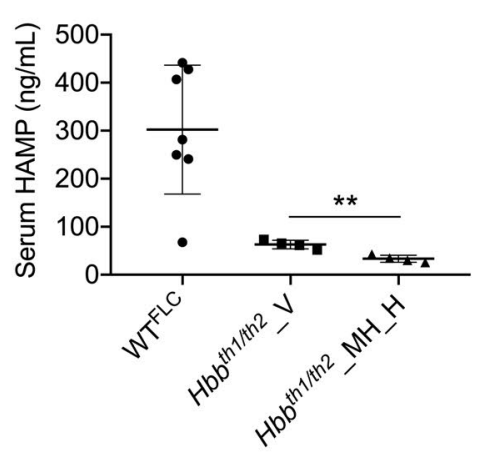

E

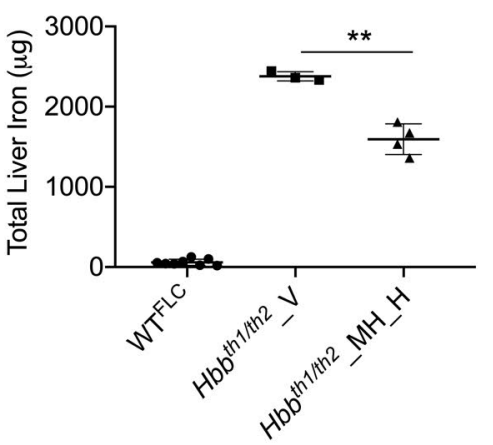

C

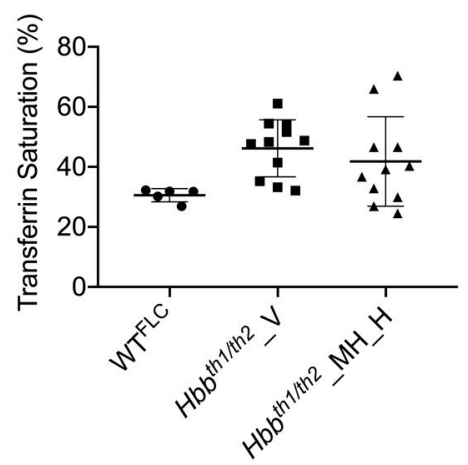

$\mathrm{F}$

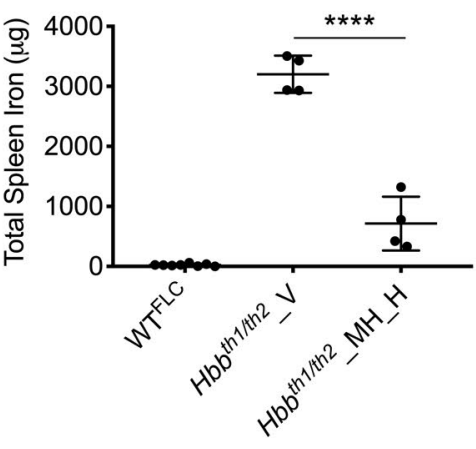

Figure 5. Serum and tissues iron analysis showed improvements in $\mathrm{Hbb}^{\text {th1/th2 }} \mathrm{BMC}$ mice after treatment with minihepcidin. In a comparison of animals treated with vehicle (V) or high-dose hepcidin (MH_H), (A) serum erythroferrone (ERFE) levels were significantly different, (B) serum hepcidin (HAMP) was decreased, (C) while transferrin saturation did not show significant differences. (D) Serum iron was significantly reduced after MH_H administration. As a result of a decreased erythroid iron uptake, total organ iron content was reduced in the (E) liver and (F) spleen, but not in the kidney (not shown). Bars represent the standard deviation. $* * * * P \leq 0.001, * * P \leq 0.01 ; * P \leq 0.05$.

A

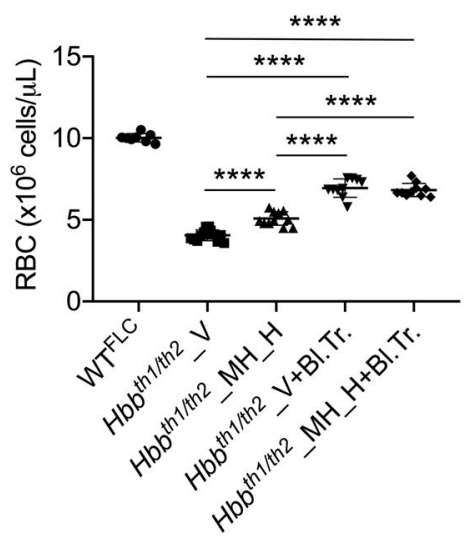

C

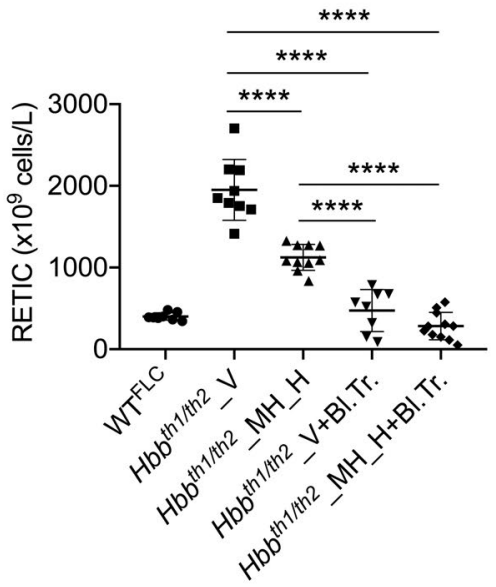

B

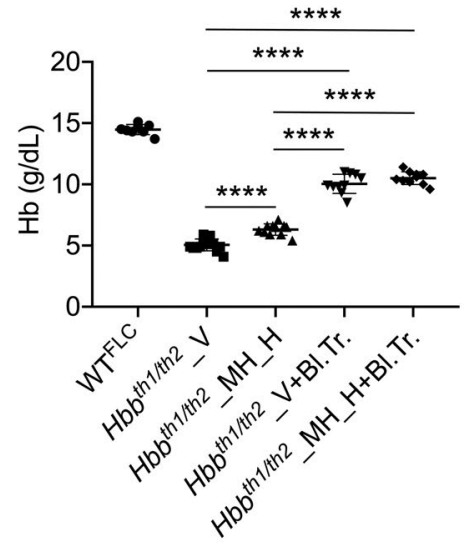

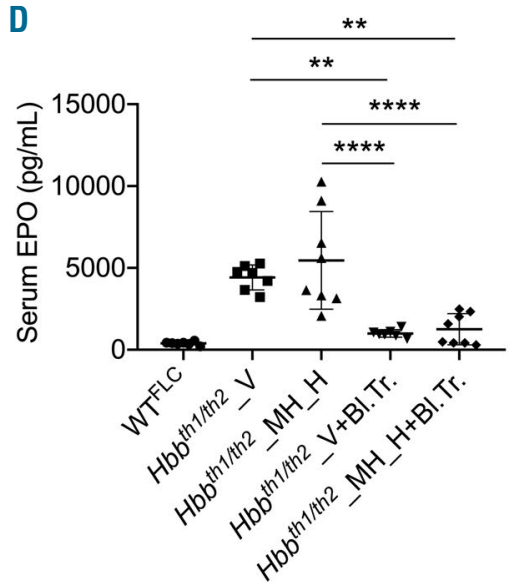

Figure 6. Minihepcidin and blood transfusion improved hematologic parameters and reduced serum erythropoietin in $H_{b} b^{t h 1 / t h 2}-B M C$ mice. Administration of minihepcidin resulted in (A) increased red blood cell (RBC) count and (B) hemoglobin $(\mathrm{Hb})$ levels, while $(\mathrm{C})$ reticulocytes (RETIC) numbers were reduced. (D) Serum erythropoietin (EPO) concentration did not show statistical differences. Bars represent standard deviation. $* * * * P \leq 0.001, * * P \leq 0.01$. WT: wildtype; FLC: fetal liver cells; V: vehicle; $\mathrm{MH} H$ : high-dose minihepcidin; BI.Tr: blood transfusion. 
A

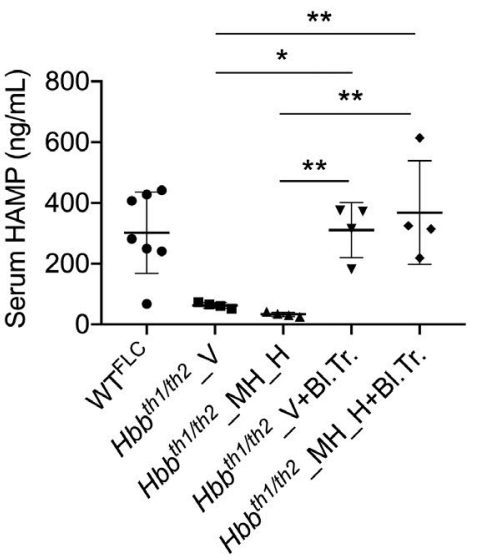

D

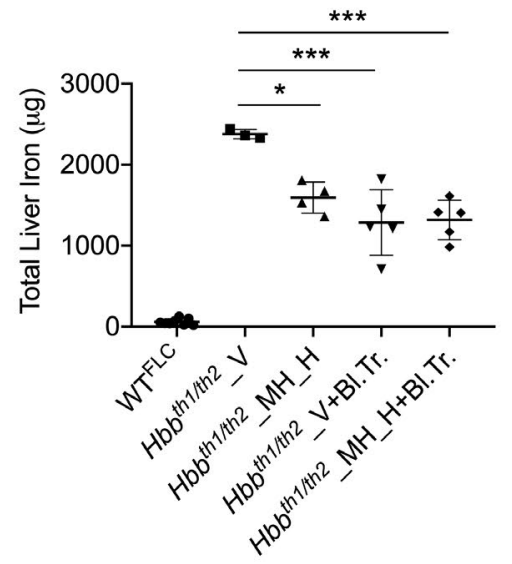

G

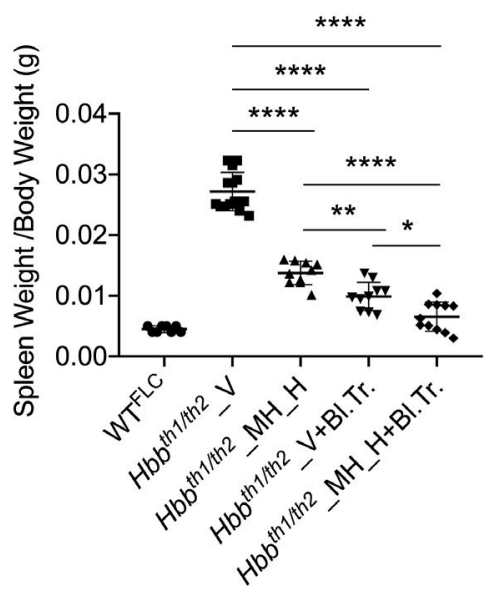

B

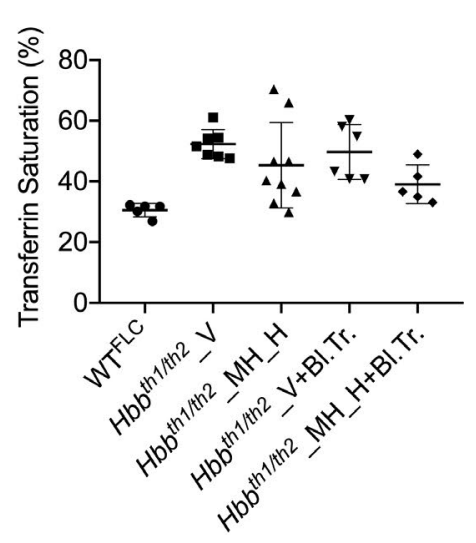

$E$

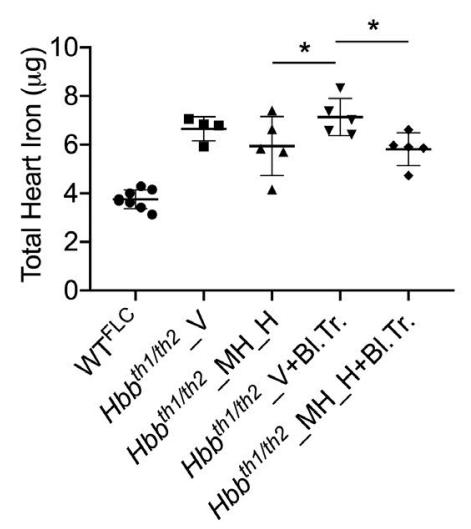

C

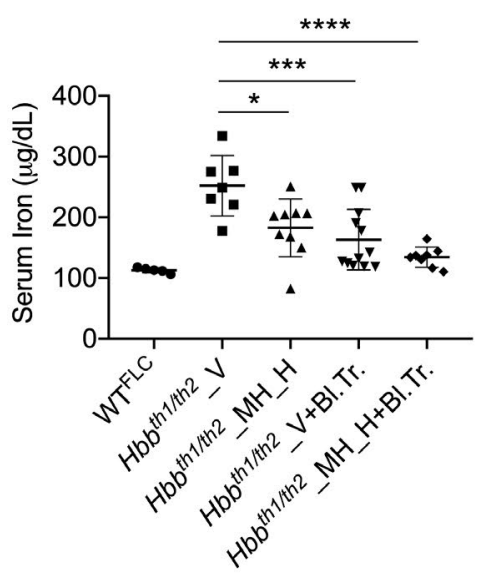

$\mathrm{F}$

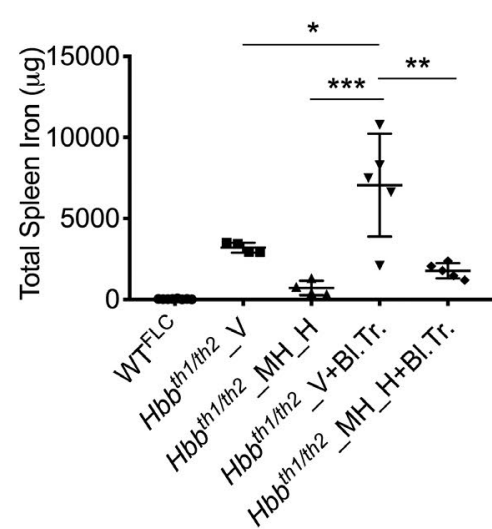

Figure 7. Improved iron parameters and splenomegaly in $H b b^{\text {th } 1 / t h 2}-B M C$ mice treated with minihepcidin and blood transfusion. (A) Hepcidin (HAMP) levels increased in the group given blood transfusions (BI.Tr.) with or without high-dose minihepcidin (MH-H). (B) Transferrin saturation levels were not statistically different in treated or untreated animals. (C) Serum iron levels were decreased in the animals given blood transfusions compared to animals treated with vehicle $(\mathrm{V})$ alone and were similar to those in animals treated with $\mathrm{MH}-\mathrm{H}$. (D) Liver iron content was decreased in animals given blood transfusions (with or without MH_H) when compared to animals treated with vehicle and similar to those treated with $\mathrm{MH}$ spleen (F) was decreased. (G) Spleen weight was almost normalized in $\mathrm{MH}$ _H- treated mice, transfused or not. Bars represent the standard deviation. $* * * * P \leq 0.001$, $* * * P \leq 0.005, * * P \leq 0.01 ; * P \leq 0.05$.

(Figure 7F, Online Supplementary Figure S7) and splenomegaly (Figure 7G), reaching levels similar to those in WT mice. Therefore, administration of minihepcidins may also be beneficial in reducing or preventing splenomegaly and organ-associated iron overload in the presence of blood transfusion.

\section{Discussion}

We crossed models of NTDT $H b b^{\text {th } 1 / \text { th } 1}$ with $\mathrm{Hb}^{\text {th2/+ }}$ to generate a combination of mutations that decreased synthesis of mouse $\beta$-globin genes to mimic TDT. These models exhibit severe anemia, high erythroferrone and low hepcidin levels in the serum, iron overload and succumbed to death due to anemia 4 months after transplantation, mimicking the most severe form of thalassemia in humans. This relatively slow progression to fatal anemia enables this model to be used to study drugs, such as minihepcidins, with the potential to modulate ineffective erythropoiesis in the presence and absence of transfusions.

The administration of a minihepicidin improved $\mathrm{RBC}$ morphology, hemichrome formation, and thus the quality of RBC, and reversed splenomegaly, ineffective erythropoiesis, and anemia in $H b b^{\text {th } 1 / \text { th } 2}$ BMC mice, our new model of TDT. Furthermore, iron parameters, such as serum, liver, and spleen iron concentration, were 
decreased in the minihepcidin-treated $H b b^{\text {th } 1 / \text { th } 2}$ BMC mice. Interestingly, serum erythroferrone levels were decreased, as expected by a reduction in the number of erythroid progenitor cells, while hepcidin level was reduced in comparison to that in untreated mice. This could be explained by the reduction in liver iron concentration, which may prevail over reduced erythroferrone levels on regulating hepcidin expression. When a minihepcidin was combined with transfusion, it further improved splenomegaly, with animals treated in this way showing an average spleen weight similar to that of WT mice. This suggests that, in TDT patients, this approach could further prevent or decrease splenomegaly, thereby reducing the requirement for splenectomy.

Interestingly, in this setting ( 6 weeks of weekly blood transfusions), we did not observe any effect of the minihepcidin on anemia (seen 6 days after the last blood transfusion). It is possible that our transfusion regimen (rate of administration, 6-week treatment and volume of blood transfused) may have been insufficient to show potential differences associated with the administration of minihepicidins. Alternatively, administration of the minihepicidin may have slightly reduced the life-span of transfused RBC (Online Supplementary Figure S8). Future studies will address whether this phenomenon is associated only with this compound or with any drug that activates or mimics hepcidin activity. Looking at the characteristics of this mouse model, different endpoints may be observed in B-thalassemic patients treated with a similar drug. For instance these animals appear to absorb more iron and produce more reticulocytes compared to humans. In addition, the amount of transfusion was limited (only 6 weeks compared to lifelong treatment in humans) and the regimen of drug administration will likely be different in young and old patients. Nevertheless, our data indicate that minihepicidin administration provides several beneficial effects in combination with transfusion, such as reducing serum and heart iron concentration, while improving ineffective erythropoiesis, and splenomegaly. Based on previous data from thalassemia intermedia mice and now from this new TDT model, we speculate that administration of minihepicidins may reduce or eliminate the requirement for transfusions by enhancing the efficiency of endogenous, more iron-restricted, erythropoiesis in several scenarios: (i) for those NTDT patients who become progressively more transfusion-dependent due to disease progression and (ii) in patients with intermittent transfusion requirements, stabilizing endogenous hemoglobin synthesis sufficiently to avoid transfusion. ${ }^{4,5,45,46}$ These potentially beneficial effects of minihepicidins may be further enhanced by combination with drugs that increase RBC synthesis, such as luspatercept or sotatercept. ${ }^{47-50}$

In conclusion, we generated a new model of TDT that can be utilized to test drugs with the potential to improve ineffective erythropoiesis and anemia. Furthermore, we demonstrate that a minihepicidin has the potential to improve erythropoiesis and iron metabolism in this model, providing pre-clinical proof-of-concept for its use also in $\beta$-thalassemic patients affected by forms of anemias more severe than those observed in NTDT.

\section{Acknowledgments}

This work was supported by Merganser Biotech and grants from the National Institute of Diabetes and Digestive and Kidney Diseases and National Heart, Lung, and Blood Institute of the National Institutes of Health: R01 DK090554 (to SR), R01 DK095112 (to RF, SR, and YZG), R01 DK107670 (to YZG). Complete blood count were analyzed by the Translational Core Laboratory of the CHOP Research Institute and the Institutional Clinical and Translational Science Award Research Center, National Center for Advancing Translational Sciences (NIH/NCATS) grant UL1TR000003.

\section{References}

1. Rachmilewitz EA, Thorell B. Hemichromes in single inclusion bodies in red cells of beta thalassemia. Blood. 1972;39(6):794-800.

2. Shinar E, Rachmilewitz EA. Oxidative denaturation of red blood cells in thalassemia. Semin Hematol. 1990;27(1):70-82.

3. Gardenghi S, Ramos P, Marongiu MF, et al. Hepcidin as a therapeutic tool to limit iron overload and improve anemia in $\beta$-thalassemic mice. J Clin Invest. 2010;120(12): 4466-4477.

4. Rivella S. $\beta$-thalassemias: paradigmatic diseases for scientific discoveries and development of innovative therapies. Haematologica. 2015;100(4):418-430.

5. Porter JB, Cappellini MD, Kattamis A, et al. Iron overload across the spectrum of nontransfusion-dependent thalassaemias: role of erythropoiesis, splenectomy and transfusions. Br J Haematol. 2017;176(2):288-299.

6. Taher AT, Weatherall DJ, Cappellini MD. Thalassaemia. Lancet. 2018;391(10116):155167.

7. Danjou F, Origa R, Anni Fet al. Longitudinal analysis of heart and liver iron in thalassemia major patients according to chela- tion treatment. Blood Cells Mol Dis. 2013;51(3):142-145

8. Taher AT, Cappellini MD. How I manage medical complications of $\beta$-thalassemia in adults. Blood. 2018;132(17):1781-1791.

9. Lal A, Wong TE, Andrews J, et al Transfusion practices and complications in thalassemia. Transfusion. 2018;58(12):28262835.

10. Musallam KM, Rivella S, Vichinsky E, et al Non-transfusion-dependent thalassemias. Haematologica. 2013;98(6):833-844.

11. Moukhadder HM, Halawi R, Cappellini $\mathrm{MD}$, et al. Hepatocellular carcinoma as an emerging morbidity in the thalassemia syndromes: a comprehensive review. Cancer. 2017;123(5):751-758.

12. Kautz L, Jung G, Valore EV, et al. Identification of erythroferrone as an erythroid regulator of iron metabolism. Nat Genet. 2014;46(7):678-684.

13. Ganz T, Jung G, Naeim A, et al. Immunoassay for human serum erythroferrone. Blood. 2017;130(10):1243-1246.

14. Arezes J, Foy N, McHugh $\mathrm{K}$, et al. Erythroferrone inhibits the induction of hepcidin by BMP6. Blood. 2018;132(14): 1473-1477.

15. Kautz L, Jung G, Du X, et al. Erythroferrone contributes to hepcidin suppression and iron overload in a mouse model of $\beta$-thalassemia. Blood. 2015;126(17):2031-2037.

16. Gardenghi S, Marongiu MF, Ramos P, et al. Ineffective erythropoiesis in beta-thalassemia is characterized by increased iron absorption mediated by down-regulation of hepcidin and up-regulation of ferroportin. Blood. 2007;109(11):5027-5035.

17. Guo S, Casu C, Gardenghi S, et al. Reducing TMPRSS6 ameliorates hemochromatosis and $\beta$-thalassemia in mice. J Clin Invest. 2013;123(4):1531-1541.

18. Aydinok Y. Iron Chelation therapy as a modality of management. Hematol Oncol Clin North Am. 2018;32(2):261-275.

19. Ginzburg Y, Rivella S. $\beta$-thalassemia: a model for elucidating the dynamic regulation of ineffective erythropoiesis and iron metabolism. Blood. 2011;118(16):43214330.

20. Anderson ER, Taylor M, Xue X, et al. Intestinal HIF2 $\alpha$ promotes tissue-iron accumulation in disorders of iron overload with anemia. Proc Natl Acad Sci U S A. 2013;110(50):E4922-4930.

21. Cappellini MD, Porter JB, Viprakasit V, et al A paradigm shift on beta-thalassaemia treatment: how will we manage this old disease 
with new therapies? Blood Rev. 2018;32(4): 300-311.

22. Cohen AR, Glimm E, Porter JB. Effect of transfusional iron intake on response to chelation therapy in beta-thalassemia major. Blood. 2008;111(2):583-587.

23. Preza GC, Ruchala P, Pinon R, et al. Minihepcidins are rationally designed small peptides that mimic hepcidin activity in mice and may be useful for the treatment of iron overload. J Clin Invest. 2011;121 (12):4880-4888

24. Ramos E, Ruchala P, Goodnough JB, et al. Minihepcidins prevent iron overload in a hepcidin-deficient mouse model of severe hemochromatosis. Blood. 2012;120(18): 3829-3836.

25. Schmidt PJ, Toudjarska I, Sendamarai AK, et al. An RNAi therapeutic targeting Tmprss6 decreases iron overload in Hfe-/- mice and ameliorates anemia and iron overload in murine $\beta$-thalassemia intermedia. Blood. 2013;121(7):1200-1208

26. Schmidt PJ, Racie T, Westerman M, et al. Combination therapy with a Tmprss6 RNAi-therapeutic and the oral iron chelator deferiprone additively diminishes secondary iron overload in a mouse model of $\beta$-thalassemia intermedia. Am J Hematol. 2015;90(4):310-313.

27. Casu C, Aghajan M, Oikonomidou PR, et al. Combination of Tmprss6- ASO and the iron chelator deferiprone improves erythropoiesis and reduces iron overload in a mouse model of beta-thalassemia intermedia. Haematologica. 2016;101(1):e8-e11.

28. Casu C, Oikonomidou PR, Chen $\mathrm{H}$ et al. Minihepcidin peptides as disease modifiers in mice affected by $\beta$-thalassemia and polycythemia vera. Blood. 2016;128(2):265-276.

29. Chen H, Choesang $\mathrm{T}$, Li H, et al. Increased hepcidin in transferrin-treated thalassemic mice correlates with increased liver BMP2 expression and decreased hepatocyte ERK activation. Haematologica. 2016;101(3):297308.

30. Huo Y, McConnell SC, Ryan TM. Preclinical transfusion-dependent humanized mouse model of beta thalassemia major. Blood. 2009;113(19):4763-4770.

31. Huo Y, McConnell SC, Liu SR, et al. Humanized mouse model of Cooley's anemia. J Biol Chem. 2009;284(8):4889-4896.

32. Huo Y, McConnell SC, Liu S, et al. Humanized mouse models of Cooley's anemia: correct fetal-to-adult hemoglobin switching, disease onset, and disease pathology. Ann N Y Acad Sci. 2010;1202:45-51.

33. McColl B, Vadolas J. Animal models of $\beta$ hemoglobinopathies: utility and limitations. J Blood Med. 2016;7:263-274.

34. Skow LC, Burkhart BA, Johnson FM, et al. A mouse model for beta-thalassemia. Cell. 1983;34(3):1043-1052.

35. Shehee WR, Oliver P, Smithies O. Lethal thalassemia after insertional disruption of the mouse major adult beta-globin gene. Proc Natl Acad Sci U S A. 1993;90(8):31773181.

36. Yang B, Kirby S, Lewis J, et al. A mouse model for beta 0-thalassemia. Proc Nat Acad Sci U S A. 1995;92(25):11608-11612.

37. Ciavatta DJ, Ryan TM, Farmer SC, et al. Mouse model of human beta zero thalassemia: targeted deletion of the mouse beta maj- and beta min-globin genes in embryonic stem cells. Proc Natl Acad Sci U S A. 1995;92(20):9259-9263.

38. Rivella S, May C, Chadburn A, et al. A novel murine model of Cooley anemia and its rescue by lentiviral-mediated human beta-globin gene transfer. Blood. 2003;101(8):29322939.

39. Libani IV, Guy EC, Melchiori L, et al. Decreased differentiation of erythroid cells exacerbates ineffective erythropoiesis in beta-thalassemia. Blood. 2008;112(3):875885.

40. Schaefer BC, Schaefer ML, Kappler JW, et al. Observation of antigen-dependent CD8+ Tcell/ dendritic cell interactions in vivo. Cell Immunol. 2001;214(2):110-122.

41. Mercier FE, Sykes DB, Scadden DT. Single targeted exon mutation creates a true con- genic mouse for competitive Hematopoietic stem cell transplantation: the C57BL/6CD45.1(STEM) mouse. Stem Cell Reports. 2016;6(6):985-992

42. Ocana MF, Neubert H. An immunoaffinity liquid chromatography-tandem mass spectrometry assay for the quantitation of matrix metalloproteinase 9 in mouse serum. Anal Biochem. 2010;399(2):202-210.

43. McAvoy T, Lassman ME, Spellman DS, et al Quantification of tau in cerebrospinal fluid by immunoaffinity enrichment and tandem mass spectrometry. Clin Chem. 2014;60(4):683-689

44. Palandra J, Finelli A, Zhu M, et al. Highly specific and sensitive measurements of human and monkey interleukin 21 using sequential protein and tryptic peptide immunoaffinity LC-MS/MS. Anal Chem. 2013;85(11):5522-5529.

45. Kohne E. Hemoglobinopathies: clinical manifestations, diagnosis, and treatment Dtsch Arztebl Int. 2011;108(31-32):532-540.

46. Oikonomidou PR, Rivella S. What can we learn from ineffective erythropoiesis in thalassemia? Blood Rev. 2018;32(2):130143.

47. Suragani RN, Cadena SM, Cawley SM, et al Transforming growth factor $\beta$ superfamily ligand trap ACE-536 corrects anemia by promoting late-stage erythropoiesis. Nat Med. 2014;20(4):408-414

48. Suragani RN, Cawley SM, Li R, et al Modified activin receptor IIB ligand trap mitigates ineffective erythropoiesis and disease complications in murine $\beta$-thalassemia. Blood. 2014:123(25):3864-3872.

49. Dussiot M, Maciel TT, Fricot A, et al. An activin receptor IIA ligand trap corrects ineffective erythropoiesis in $\beta$-thalassemia. Nat Med. 2014;20(4):398-407.

50. Cappellini MD, Porter J, Origa R, et al. Sotatercept, a novel transforming growth factor $\beta$ ligand trap, improves anemia in $\beta$ thalassemia: a phase 2, open-label, dosefinding study. Haematologica. 2019;104(3): 477-484. 